\title{
Nondestructive test methods for concrete bridges: A review
}

Sardar Kashif Ur Rehman, Zainah Ibrahim, Shazim Ali Memon, Mohammed Jameel

- Department of Civil Engineering

\begin{abstract}
NDT methods applicable to concrete bridges are reviewed. The methodology, advantages and disadvantages along with up to date research on NDT methods are presented. Different damage levels, having less dependence on inspector judgment, are suggested. Moreover, a flow chart based on damage level along with NDT methods and potential remedial measures are proposed for periodic health monitoring of structures. NDT methods are also suggested to address specific problems related to structures. Finally, the relation between some of the well-known NDT methods and most common problems encountered by the field engineers is proposed. Hence, the importance of structural health monitoring is highlighted.
\end{abstract}

Original language

English

Pages (from-to)

$58-86$

Number of pages

29

Journal

Construction and Building Materials

Volume

107

State

Published - Mar 152016

Kashif Ur Rehman, S., Ibrahim, Z., Memon, S. A., \& Jameel, M. (2016). Nondestructive test methods for concrete bridges: A review. Construction and Building Materials, 107, 58-86.

DOI: 10.1016/j.conbuildmat.2015.12.011 